SIR,-Minor structures in the basal Wenlock beds of Co. Mayo are extremely variable, particularly when it is studied as a whole; they include, among others, the steep westerly-plunging folds, mentioned by Mr. Dewey, especially in the matrix of the conglomerate. Moreover, the relation of boulder extension to structure is a controversial problem; the stretching of the boulders can also be interpreted as in $a$ " $b$ " direction parallel to the E.-W. folds including, in part of the S. limb, those plunging gently east.

There is a tendency to regard every different direction of minor structure as evidence of the existence of a separate fold-system irrespective of the nature of the formations and the geometry of their mapped boundaries, whereas minor structures, in different directions, even showing a local sequence, may develop within the one system. The complex structures in the highly inhomogeneous Wenlock conglomerate may well fall into this category; discussion of their possibly wider tectonic significance must await the publication of more detailed evidence than is possible in a letter.

No evidence whatever is afforded for the supposed tectonic effects of the granite. However, consideration of the position of the intrusion in relation to the symmetry of the arc it cuts does not support the view that it is the cause of the arcuate swing. Moreover, detailed mapping, both on its W. margin and on its complex N. margin, shows structures and stratigraphical boundaries striking straight at granite junctions.

Having ascribed the east arm of the Cregganbaun arc to this cause, $\mathrm{Mr}$. Dewey then invokes a second cause for the west arm. (Yet a third must be postulated for the arcing and N.W. folds remote from both granite and fault.) Dr. Stanton, it is true, attributes certain tectonic features in the Ordovician further S. to the Maam faults, but he has not " undoubtedly " shown that the swing in strike N.W. of Cregganbaun is due to these structures.

The Maam fractures are in fact part of a system of N.W. and N.E. tear faults which developed very late and may in fact be due to post-Carboniferous, N.-S. Armorican compression ; the arcs, on the other hand, are pre-Carboniferous. These faults are plentiful throughout a wide region and very commonly cut across formations with only very local drag or shear (as do the Maam Faults for part of their course). Where, however, a pre-existing grain approximately in the potential shear-direction exists, a fault will more readily and fully develop, as has happened in the case in question; this does not exclude the possibility of some shearing parallel to the fault-movement.
Department of Geology,
J. G. C. ANDERSON.

University College, CardifF.

18th October, 1960.

\title{
DEPTH TO TOP OF POSTULATED WEARDALE GRANITE
}

SIR,-Gravity surveys have revealed a region of negative Bouguer anomalies over the northernmost Pennines (the Alston Block) which is unrelated to the known geological structure and has been interpreted by Bott and MassonSmith (1957) as being caused by a buried granite (named the Weardale granite). At that time the top surface of the granite was estimated to be less than 5,000 feet deep. Since the publication of this paper certain advances have been made in the technique of depth estimation from gravity anomalies, and I should like to put on record an improved estimate before it is put to the test in a new borehole which is now being drilled at Rookhope, Co. Durham.

A method of depth estimation recently developed by Smith (1959) relies only on the measured second or third derivatives of the Bouguer anomalies and an assumed value for the density contrast. This method gives considerably " better" estimates than earlier methods (e.g. Bullard and Cooper, 1948; Bott and Smith, 1958) and has the added advantage that knowledge of the background gravity field is not needed. The estimates give maximum possible depths for the assumptions stated and refer to the top surface of the anomalous body and not to its centre of gravity or base. Therefore the estimate must be treated as a limit and not as the expected depth. 
Smith (1959) has shown that the maximum possible depth to the top of a gravitating body can be estimated from either of the following formulae (slightly adapted) :-

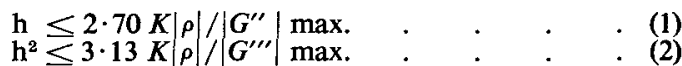

where $K$ is the gravitational constant, $\rho$ is the difference between the maximum and minimum densities of the system, $G^{\prime \prime}$ max. is the maximum observed second horizontal derivative of the gravity anomaly, and $G^{\prime \prime \prime}$ max. is the maximum observed third horizontal derivative.

If two-dimensional shape can be assumed, formula (1) can be improved by about 4 per cent, as follows:-

$$
\mathrm{h} \leq 2 \cdot 60 \mathrm{~K}|\rho| /\left|G^{\prime \prime}\right| \max .
$$

Thus the two-dimensional limiting case is very little different from the three-dimensional limiting case.

A two-dimensional shape exactly satisfying the limiting condition of equation (3) can be constructed as follows. The limiting body (shown in Text-fig. 1) is a symmetrical truncated wedge of uniform density $\rho$ with

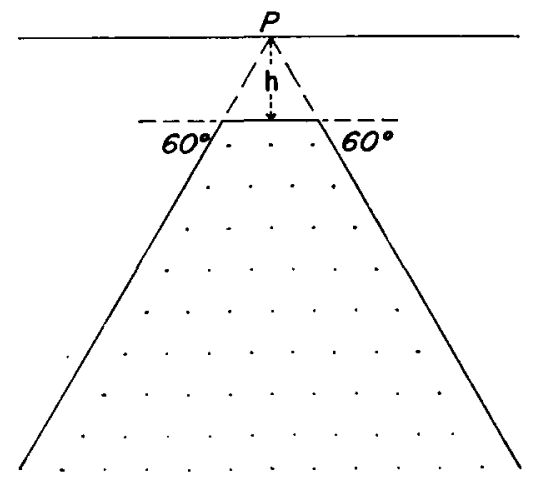

TEXT-FIG. 1.-The two-dimensional shape satisfying the limiting condition of equation (3). The stippled portion has a uniform density contrast $\rho$ to the remaining unshaded part and the model extends uniformly to an infinite depth.

a vertical axis. The depth to the truncated top surface, which is horizontal, is $h$. The edges both dip at $60^{\circ}$ (in opposite directions) and the wedge extends to an infinite depth. The maximum value of the second derivative of gravity then occurs at the apex of the wedge (P), and its value is given exactly by equation (3). For any other two-dimensional shape equation (3) gives an overestimate of $h$.

In this limiting case, each edge contributes equally to the maximum second derivative. If, therefore, one of the edges is sufficiently distant to contribute negligibly to the total second derivative, then we obtain the following limiting formula for a two-dimensional step :-

$$
\mathrm{h} \leq 1 \cdot 30 \mathrm{~K}|\rho| /\left|\mathrm{G}^{\prime \prime}\right| \max .
$$

This formula is of considerable practical use, since the contribution to the second derivative from the more distant edge of many typical geological rock masses is often almost negligible. Such is the case for the postulated Weardale granite.

Detailed gravity traverses have recently been made across the margins of the Weardale anomaly to obtain accurate estimates of the numerical 
characteristics needed for depth estimation (Text-fig. 2). The maximum observed second derivative along the Stanhope-Cotherstone road was found to be $4.3 \mathrm{mgals} / \mathrm{mile}^{2}$, and if all possible errors are taken into account this value could possibly be reduced to $3.5 \mathrm{mgals} / \mathrm{mile}^{2}$. The maximum observed third derivative is $7 \cdot 5( \pm 1 \cdot 0) \mathrm{mgals} / \mathrm{mile}^{3}$.

In applying Smith's method to the Weardale anomaly, it is assumed that no appreciable errors have been introduced in making the reductions and that the observed characteristics are entirely caused by the body under study.

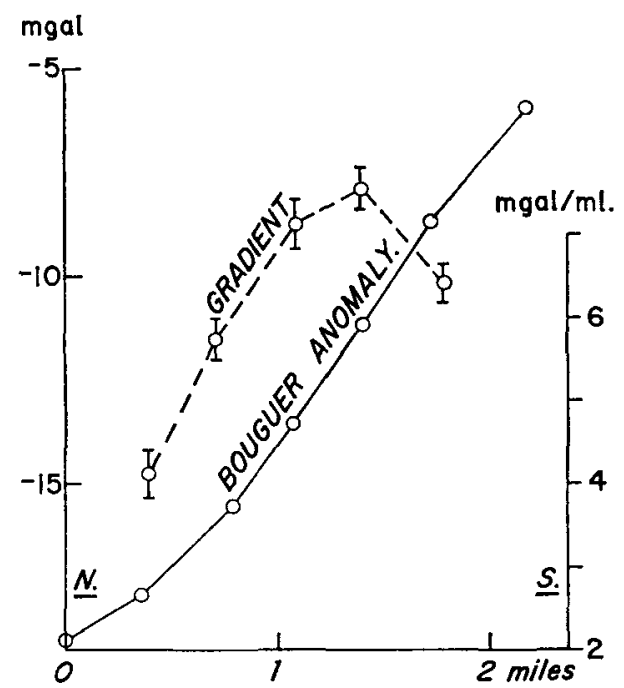

TexT-Fig. 2.-The critical part of the gravity traverse along the StanhopeCotherstone road, showing Bouguer anomalies reduced for a rock density of $2 \cdot 60 \mathrm{~g} . / \mathrm{cm}^{3}$ and the horizontal gradient of gravity. Each value of the gradient has been measured between alternative stations and for each the range of error which might be expected is shown.

In this latter respect, the Lower Carboniferous rocks exposed at the surface are practically flat-lying and unfaulted, and no thick superficial deposits are known along the line of the observed profile. The vertical variation of the Bouguer anomalies has also been taken into consideration. It is further assumed that the density contrast does not exceed $0.20 \mathrm{~g} . / \mathrm{cm}^{3}$. If the density contrast is greater (which would be unusual for a granite), the maximum possible depth estimate increases proportionately. It is clear that the northern margin of the anomalous body is sufficiently far away for its effect to be negligible; therefore inequality (4) can justifiably be used.

The results, taking into account the likely and minimum possible observed second derivatives, are as follows :-

for $4 \cdot 3 \mathrm{mgals} / \mathrm{mile}^{2}$, depth to top surface $\leq 3,400$ feet for $3.5 \mathrm{mgals} / \mathrm{mile}^{2}$, depth to top surface $\leq 4,200$ feet

This estimate can be checked by using inequality (2) for the observed third derivative of $7.5 \mathrm{mgals} / \mathrm{mile}^{3}$, giving a maximum depth to the top surface of 5,000 feet.

Good estimates of depth can also be obtained by assuming a regular shape 
for the body and investigating by methods of trial and error how deep the body may be to give the observed amplitude of anomaly and the observed marginal gradients. While this method is not rigorous, it is likely to be reasonably reliable. Comparison of the observed Weardale profile with two-dimensional computed profiles (using the Durham University electronic computer) suggests that for a density contrast as great as $0.20 \mathrm{~g} . / \mathrm{cm} .{ }^{3}$, the observed marginal gradients of 7.5 mgals/mile could only occur if the top is about 3,500 feet or less below the surface.

In extending these deductions to Weardale and Rookhope, both of which are north of the critical profile, it is assumed that the top surface of the granite does not become appreciably deeper towards the centre of the mass. Detailed studies on the gravity anomaly suggest that this assumption is broadly correct. Nevertheless local fluctuations could occur without noticeably affecting the anomalies.

It is concluded that the top surface of the postulated Weardale granite is shallower than about 4,000 feet beneath the Stanhope-Cotherstone road, about $4 \frac{1}{2}$ miles south of Stanhope. Taking into account the variation in topographic height, the top of the granite should be less than 3,500 feet beneath Weardale and less than 4,000 feet beneath Rookhope provided the stated assumptions are correct. It is not possible from the gravity anomalies to place a minimum limit on the depth although absence of metamorphic effects at the surface suggests it is at least 1,500 or 2,000 feet deep. Thus it is expected that the granite will be reached in the Rookhope borehole between depths of 1,500 and 4,000 feet and most likely between 2,000 and 3,000 feet.

\section{REFERENCES}

Bott, M. H. P., and D. Masson-Smith, 1957. The geological interpretation of a gravity survey of the Alston Block and the Durham Coalfield. Quart. J. geol. Soc. Lond., 113, 93-117.

BotT, M. H. P., and R. A. Smith, 1958. The estimation of the limiting depth of gravitating bodies. Geophysical Prospecting, 6, 1-10.

Bullard, E. C., and R. I. B. CoOper, 1948. The determination of the masses necessary to produce a given gravitational field. Proc. Roy. Soc., 194A, 332-347.

SmITH, R. A., 1959. Some depth formulae for local magnetic and gravity anomalies. Geophysical Prospecting, 7, 55-63.

M. H. P. BotT.

\section{Department of Geology, \\ SOUTH ROAD, DURHAM.}

10th October, 1960.

\section{FEEDING MECHANISMS OF SPIRE-BEARING BRACHIOPODS}

SIR,--The recent article by Dr. M. J. S. Rudwick on " The feeding mechanisms of spire-bearing fossil brachiopods" is a splendid example of the bold and imaginative use of living material to infer the habits of extinct groups and will certainly be appreciated by all those who decry the rarity of this event in palaeontological practice. But a sincere welcome for the approach is not necessarily an unqualified approbation of the conclusions which, as outlined below, appear to involve some inadequately considered assumptions.

Having demonstrated in 1956 that the internal skeleton of the brachiopod is secreted by outer epithelium in the same way as the secondary shell layer, I can only concur with Rudwick's reiteration that the growth of the lophophore and its calcareous support are independent functions. This, however, does not preclude the intimate connection of one with the other. It is significant, for example, as Mr. A. D. Wright and I have recently said in an article on the origin of the loop (now in press-Palaeontology) that even in the 